\title{
INTERSTITIAL NEURITIS AND THE NEURAL THEORY OF FIBROSITIS*
}

\author{
BY \\ MICHAEL KELLY \\ Department of Anatomy and Histology, University of Melbourne, Victoria, Australia
}

Interstitial neuritis, or fibrositis of the sheath of a nerve trunk, is characterized by five chief signs or symptoms (Harris, 1926; Walshe, 1943) : (1) radiating pain; (2) tenderness in the vicinity of a nerve trunk; (3) paraesthesiae or objective sensory loss; (4) muscular wasting or paresis; (5) loss of deep reflexes.

If the distribution of the pain and tenderness, however, is such as to suggest the involvement of a nerve trunk, the diagnosis may be made in the absence of the remaining three criteria. Motor and sensory signs are encountered in only a minority of cases (Walshe).

\section{The Pathology of Interstitial Neuritis}

"Of the pathological process which underlies this familiar affection," wrote Walshe, " relatively little is known, but it involves the interstitial tissues of the nerve roots and trunks and not, save secondarily in some cases, the nervous elements." Symonds (1943) contends that its pathology is built upon guesswork, for the neurologist rarely sees the nerve which is supposed to be affected. Purdon Martin (1933) thought that the pain of neuritis could not be produced solely by pressure upon axis cylinders; he suggested that it must be related to an altered state of the nervi nervorum. The orthodox view holds that the rheumatic inflammation of the sheath, with its consequent swelling, interrupts the neuraxons by mechanical pressure. It is not necessary, however, to postulate such a mechanical element, for the rheumatic agent is well known to be capable of bringing about the death or degeneration of specialized tissues. If we agree that the fibrositic process may attack the fibrous sheath of a nerve, it follows that the nerve fibres may be poisoned by the diffusion of the rheumatic agent. Bentley and Schlapp (1943) demonstrated that the pressure necessary to interrupt conduction in a nerve trunk is very much greater than any that could develop in an inflam-

* This paper is part of the Buckston Browne Prize Essay for 1946, the title of the essay being "The Pathology and Treatment of Fibrositis". matory swelling; and here we have no proof that there is even any swelling.

Taking the five criteria in order, it will be seen that interstitial neuritis often is not easy to differentiate from fibrositis.

Radiating Pain.-Pain from deep somatic lesions radiates in a characteristic fashion. Thus, pain from a lesion in the shoulder-girdle may radiate to the elbow and even to the fingers. In spite of what is commonly believed, too, pain is not a characteristic feature of pressure on nerve trunks (Head and Sherren, 1905). The observer can verify this in a short time by compressing his own ulnar nerve at the elbow. Local tenderness can be elicited, of the same order as that of a musculo-tendinous junction; while the sensation which radiates to the hand is not pain, but tingling and warmth. The fact that a "neuritic" pain radiates, therefore, does not necessarily signify the presence of a lesion of a nerve trunk.

Deep Tenderness.-The diagnosis of neuritis is confirmed by the presence of tenderness of the nerve trunk, limited to it. But most nerves are not directly palpable; when diffuse tenderness occurs in the region of a nerve trunk, it should be remembered that the nerve lies deep to structures which themselves are tender. This tenderness, moreover, may be of a secondary nature, disappearing upon anaesthetization of a somatic lesion which bears no relation to the nerve trunk. Such a result has been secured with procaine in a number of cases which fulfilled the first two criteria of interstitial neuritis; in none of them did injection of the lesion cause blocking of the nerve (Kelly, 1945, 1946a and $b$ ). Tenderness in the region of a nerve trunk, said Harman (1940) is not necessarily due to primary inflammation of the nerve, for equally tender spots can be demonstrated far from the nerve.

Paraesthesiae or Objective Sensory Loss.-Tingling in the extremities, or other abnormal sensations, may result from deep lesions (Kellgren, 1938, 1939). Hyperalgesia of the skin is not pathognomonic of a nerve lesion, for it appears as an occasional reflex effect of a deep somatic lesion. Anaesthesia or 
hypo-aesthesia, however, usually is regarded as presumptive evidence of interruption of nerveconduction.

Muscular Wasting and Paresis.-Muscular wasting alone is not evidence of a trunk lesion, for reflex wasting occurs in disease of joints, and sometimes rapid wasting follows mild trauma to a muscle (Case 10). Paresis of a muscle, however, is evidence of mechanical interference with neuraxons.

Loss or diminution of deep reflexes is generally held to be pathognomonic of a nerve lesion. The work of Gellhorn and Thompson (1944), however, suggests that these effects may result also from local abnormalities of muscle (vide infra).

\section{Differences between Neuritis and Traumatic Nerve Lesions}

Interstitial neuritis, therefore, should not be diagnosed unless muscular paresis or objective sensory loss is evident. The criteria which distinguish fibrositis of a nerve sheath from intramuscular fibrositis are those of a nerve lesion, and a nerve lesion should not be diagnosed when they are absent. If there is a localized lesion affecting the nerve trunk, the signs should closely resemble those of a traumatic "lesion in continuity", in which injury has caused interruption of conduction without severing the nerve. While this close resemblance does exist in many cases, in some others the general picture of fully developed neuritis differs in four important details from that of injury to a nerve trunk: (1) pain; (2) delayed onset; (3) anatomical distribution of manifestations; (4) amount of final recovery.

Pain.-While severe pain is a characteristic feature of neuritis, it is not so in nerve injury. In only three out of twenty-four cases of " neurapraxia " reported by Seddon (1943) was pain prominent. Pain was not a feature of the cases of injury to the brachial plexus which Clausen (1942) reported, while all of Richardson's series (1942) of "winged scapulae" of non-traumatic origin were accompanied by severe pain. Pain is an added feature of neuritis, to be expected because fibrositis is a painful disorder, whether or no a nerve-sheath is involved.

Delayed Onset.-When a nerve is involved in an injury, the evidence of paralysis usually comes on rapidly. In many cases neuritis follows injury or other damage to tissues; but the onset usually is delayed for some days, and often for some weeks (see Cases 2, 6, 7, 9, 11, 12). This usually is explained as the time during which the process has been spreading to involve the nerve sheath.

Anatomical Distribution of Manifestations.-When a nerve has been injured, the motor and sensory signs usually are related only to the field of the nerve.
When, on the other hand, similar effects result from neuritis, they often overflow into the fields of other nerves. In Case 1, for example, a lesion of the circumflex nerve had overflowed to affect branches of the posterior cord of the brachial plexus.

CASE 1.-A Private, after a sore throat, suffered from pain in the right shoulder, with weakness of abduction. Seven weeks later he presented: (a) profound wasting of the deltoid, with minimal voluntary contraction; (b) diffuse deep tenderness over the acromion and the upper part of the deltoid; diminution of cutaneous sensibility in the areas supplied by the circumflex nerve and the digital branches of the radial nerve.

A year later there was no residual wasting, though he complained of weakness and aching pain.

In Case 2 a posterior cord lesion could not be diagnosed because of the damage to the suprascapular nerve, which is a branch of the upper trunk. The disorder can be explained only as a lesion of several roots.

CASE 2.-A Warrant Officer injured his right shoulder, and for some weeks suffered from a pain which radiated from the shoulder to his right ear. Later it was replaced by a pain in the left shoulder, which radiated to the wrist. The muscles of the left forearm were weak. Three months after the original injury he presented no sensory loss; but all the muscles supplied by the dorsal interosseous nerve were paretic and grossly wasted. In addition, the left deltoid and infraspinatus had undergone gross atrophy.

Similar cases of neuritis of the brachial plexus have been reported in British and Dominion Armies (Burnard and Fox, 1942; Richardson, 1942; Spillane, 1943). Bilateral lesions wère reported in seven of Spillane's forty-seven cases, and in two of Richardson's nine. In Case 3, bilateral lesions of unknown origin were seen.

CASE 3.-A Private complained of pain in his left shoulder, which shifted to the right after two weeks, with limitation of abduction of the right humerus. Six weeks from the commencement he presented: (a) "winging " of the right scapula, with weakness of abduction; (b) profound wasting of the left spinati.

In some cases large patches of anaesthesia may be seen, with no relation to any radicular or peripheral nerve distribution. These cases often are labelled hysteria because they cannot be explained upon anatomical grounds.

CASE 4.-This was a case of musculo-cutaneous neuritis with widespread hypo-aesthesia. A Private had numbness and weakness of the right arm which came on without apparent cause. The forearm felt numb, and flexion of the elbow was feeble. There was no voluntary contraction in the biceps; but the brachialis retained slight contractility. Cutaneous pain and touch were diminished or absent below a line running obliquely from two inches below the lateral epicondyle to two 
inches above the medial. The degree of loss varied in a patchy manner, and sensation was normal on the palmar surfaces of the digits. Complete recovery occurred in two months.

The Amount of Final Recovery.-After a traumatic "lesion in continuity", in which the neural pattern is not disturbed, recovery usually is complete. Seddon reported poor results in only thirteen out of 230 such lesions; while Sunderland (1945) found that the final outlook was good in a series of cases of pressure-palsy of the radial nerve.

In interstitial neuritis, on the other hand, the results are worse; thus Bennett (1939) found that 20 per cent. of 115 cases of " horse serum neuritis" were left with residual disabilities; the results reported by Burnard and Fox and by Spillane were not any better. Of the present series of 63 cases of interstitial neuritis, at least seventeen had not recovered fully within periods varying from one to three years. Such a lesion as occurs in neuritis must of a certainty be a "lesion in continuity"; yet exploration of the nerve never has revealed a macroscopic lesion, and the few microscopic examinations which have been performed have given negative results. Neuraxons possess almost irrepressible powers of regeneration so long as they retain functional connexion with the parent cells. The picture of interstitial neuritis which has failed to recover, therefore, is not consistent with the supposition that a localized lesion of a nerve has occurred. The wasting sometimes is so profound and so enduring that one is reminded of the sequelae of poliomyelitis.

\section{The Causation of Interstitial Neuritis}

The causes of interstitial neuritis are the same as those of fibrositis in general. It may occur as a manifestation of generalized rheumatism, or it may come on without apparent cause. Of the present series of sixty-three cases, in forty-six the onset could be related clearly to a causative factor. In thirty-three the cause was local, while in the remaining thirteen the neuritis followed systemic disease, or trauma to a distant region. Of the local causes, trauma, muscle strain, or infection were the agent in twenty-four, synovitis or osteo-arthritis of a neighbouring joint in five, herpes zoster in three, and subcutaneous lipomata in one. Of Spillane's forty-seven cases of brachial neuritis, twenty-seven occurred in patients already under treatment in hospital for other disorders, such as systemic infections and septic wounds. Local causes seem more significant where only one nerve is involved, as in five cases reported by Nielsen (1939), in which paralysis followed a single muscular effort. Ecker and Woltman (1938) were able to find local causes in sixty-one out of 150 cases of " meralgia paraesthetica."

Local injury, or other damage to tissues, thus plays a large part in the causation of interstitial neuritis. In most of those which followed injury, the nerve could not have been involved in the primary damage. In sixteen cases the manifestations which followed local injury or disease had spread more widely, so that they could not be explained upon the basis of simple lesions of nerve trunks. In several cases (of which Case 11 is an example), it was possible, by the use of local analgesia, to relieve temporarily or to cure the pain, without intensifying the partial block of the nerve. Seldom, indeed, was the deep tenderness of the myalgic lesion in the vicinity of any nerve trunk.

\section{The Reflex Theory Applied to the Manifestations of Neuritis}

The signs and symptoms of interstitial neuritis have been listed under five headings. Of these the first two, (1) radiating pain, and (2) deep tenderness, are reflex effects, for the injection of procaine into a myalgic lesion brings about their immediate disappearance. Sensory and motor disturbances, however, must be regarded as presumptive evidence of a nerve lesion. But in some of these cases the signs would spread far beyond the field of the trunk which seemed to be implicated. In these the older writers used to suppose the existence of an " ascending neuritis", whose pathology was obscure. It is certain, at any rate, that the orthodox conception of neuritis is not sufficient to explain the spreading nature of the manifestations. It is opportune now to inquire if they can be accounted for adequately by the reflex hypothesis recently suggested for fibrositis (Kelly, 1945, 1946 $a$ and $b$ ).

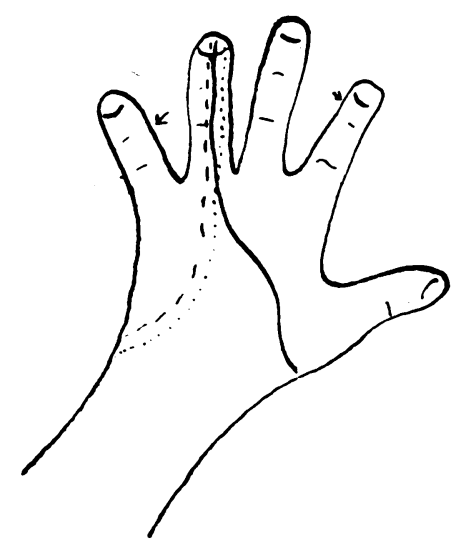

FIG. 1. 
Abnormal Cutaneous Sensation.-The late Sir Thomas Lewis (1942) observed that faradization of a digital nerve resulted in hyperalgesia through the distribution of the main cutaneous nerve (Fig. 1). Again, antidromic stimulation of a sensory trunk gave rise to hyperalgesia throughout its distribution. A good deal of converging evidence suggests that these effects are brought about through the medium of the pain nerves and their receptors. Similarly, cutaneous hyperalgesia sometimes resulted from artificial deep lesions; this Lewis regarded as a reflex effect, the nervous impulses overflowing from the deep into the cutaneous system. Though this work has rendered familiar the idea of the reflex production of hyperalgesia, the concept of reflex production of anaesthesia might seem far-fetched. But Thompson (1931) reported some years ago that faradization (through the skin) of a cutaneous nerve resulted in anaesthesia in its distribution; he made use of this method in outlining the areas of distribution of sensory nerves. At the same time Adrian and others (1931) reported experiments which suggested that the mechanical stimulation of touch receptors in the frog's skin resulted, through reflex action, in the diminution of activity in adjacent receptors. All of these observations are consistent with the supposition that abnormalities of cutaneous sensation may be a reflex effect of the activities of somatic tissues. The observations of Thompson are not inconsistent with those of Lewis, for it is a recognized neurological principle that hyperalgesia and anaesthesia may represent two different stages of the same pathological process (Kinnier Wilson, 1927).

In the condition called Sudeck's atrophy or posttraumatic painful osteoporosis, large patches of cutaneous anaesthesia may be found which do not correspond with the distribution of any nerve (Livingston, 1943; Miller and De Takats, 1942). These were regarded as the effects of reflex impulses. Sometimes a patch of anaesthesia was confined to the field of a cutaneous nerve; this Miller and De Takats regarded as evidence of involvement of the nerve trunk in the original injury. Having admitted the hypothesis of reflex anaesthesia, however, it would seem permissible to regard these also as reflex effects, confined more accurately to the distribution of a single nerve.

CASE 5.-This was a case of reflex anaesthesia following sprain of the external lateral ligament of the knee joint. A driver injured his right knee in a derailment accident. The joint was stiff and painful a month later, with nocturnal aching and much limitation of movement. The pain was felt on the outer side of the knee, and the skin all around the joint felt numb. On examination the joint was not swollen. Only $15^{\circ}$ of flexion was possible.
The outer aspect of the joint-line was extremely tender to pressure. Cutaneous sensations of touch and pain were almost completely abolished over an area surrounding the limb and extending both above and below the jointline for a distance of four inches (Fig. 2).
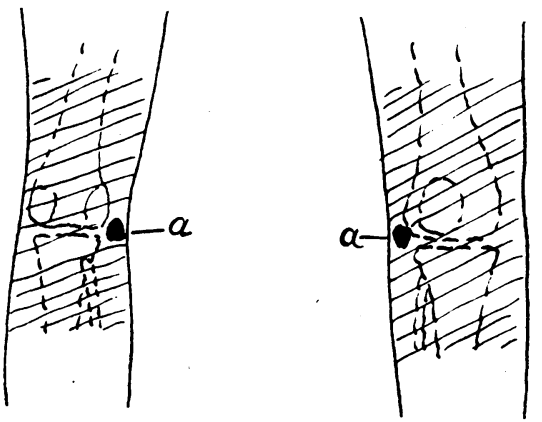

FIG. 2.

CASE 6.-This case showed anaesthesia in the distribution of the lateral cutaneous nerve of the thigh, following injury to the knee. A soldier sprained his right knee, which became distended with fluid. It was slow to recover, and after two months he complained of numbness of the thigh. Examination revealed: (1) a knee joint distended with fluid; (2) gross wasting of the quadriceps femoris; (3) anaesthesia in the distribution of the lateral cutaneous nerve. The skin was smooth and atrophic (Fig. 3).

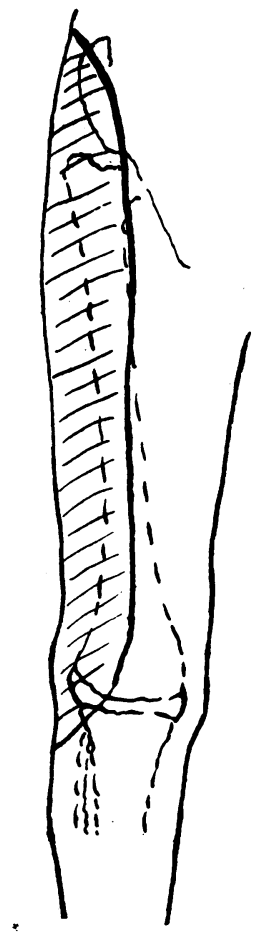

FIG. 3. 
CASE 7.-This was a case of neuritis of the lateral cutaneous nerve of the thigh, the reflex effect of multiple lipomata. A young soldier complained that for 2 years he had had painful lumps on his abdomen and right thigh. The skin over each lump on the abdomen was itchy, and the thigh had a "pins-and-needles" feeling over a larger area, with an aching pain which was made worse by weight-bearing. Examination revealed : (1) on the abdomen: four subcutaneous lipomata, each of which was surrounded by an area of cutaneous hyperalgesia; (2) on the right thigh seven lipomata more closely grouped, with an area of hyperalgesia occupying the outer surface of the thigh, and extending from the iliac crest to the level of the knee joint (Fig. 4).

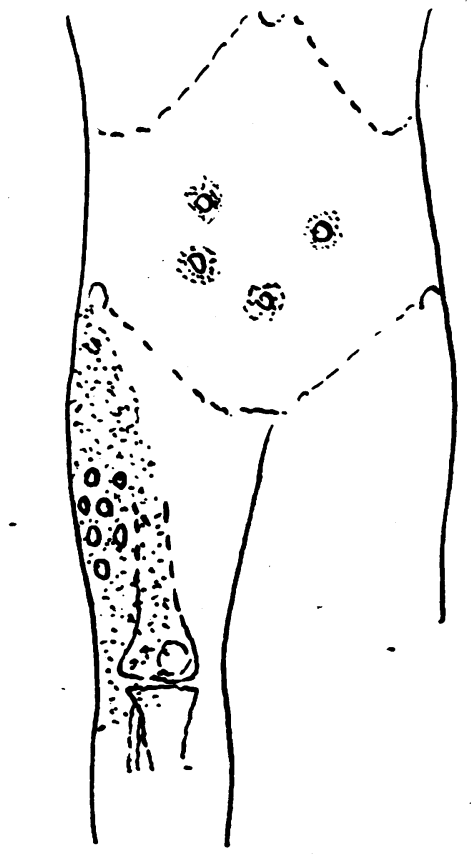

Fig. 4.

Case 7 provides strong support for the reflex theory of neuritis. The small patch of hyperalgesia around each isolated lipoma must have been a reflex effect from the tumour. On the thigh, where the lumps were more numerous and grouped more closely, the areas of hyperalgesia had enlarged and coalesced, and spread to involve the whole distribution of a large cutaneous nerve.

CASE 8. - This case had ulnar anaesthesia after mild crushing injury to the hand. A seaman suffered a slight crushing injury to the hand in February, 1942. Since then it had been painful, with an ache ascending along the inner side of the forearm. Late in June he complained of severe pain and of numbness in the hand and lower part of the forearm. On examination seven months after the injury, anaesthesia was found in the distribution of the ulnar nerve in the hand, spreading upwards for six inches along the ulnar side of the forearm. A point of acute tenderness was found in the fourth interosseous space (Fig. 5).

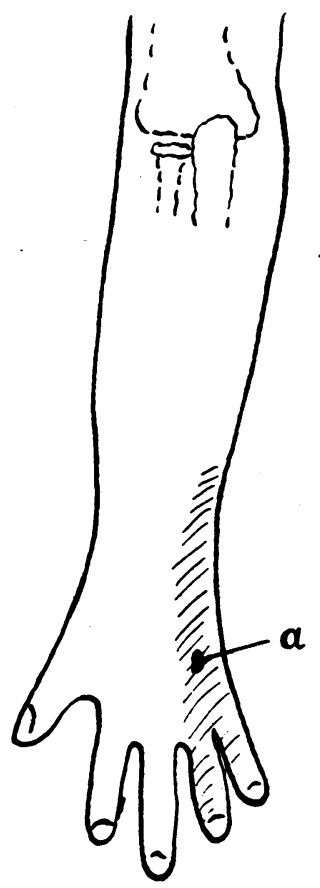

Fig. 5.

CASE 9.-This case had a partial lesion of the dorsal cutaneous nerve of the forearm after fracture of the lower end of the radius. A Sergeant fractured the lower end of his radius. Plaster was applied, and removed seven weeks later. For two months after this the wrist remained stiff, with a tendency to swell on the dorsum. He complained of an ache at night, with pain shooting along the dorsum of the forearm. On examination there was found to be cutaneous hyperalgesia of the distal half of the dorsum of the forearm. Movements of the wrist were limited by a painful stiffness, though the fracture had united normally. The pain in the forearm was completely abolished by injecting with procaine a tender spot in the extensor mass near the musculo-tendinous junction.

A number of like cases could be cited, and all indicate that reflex sensory effects may approximate to the distribution of a cutaneous nerve. In other cases they are more diffuse, resulting in anaesthesia of a more irregular distribution (as in Cases 4 and 5).

Paralysis and Wasting of Muscles.-These are signs of interference with the lower motor neurone. In interstitial neuritis, complete paralysis is encountered only occasionally, and wasting may be absent. In the profound wasting which sometimes 
accompanies joint disease, groups of muscles are involved which are functionally connected with the joint, and reflex activity may be increased. "It is not a mere wasting from disuse," said Sir James Paget (1879), " it is far more rapid than that; . . . I wish I could explain it better than by calling it reflex atrophy ... due to the disturbance of some nutritive nerve centre, irritated by the painful state of the sensitive nerve fibres." In experiments on rabbits, Harding (1929) was able to show that this reflex wasting depended upon the integrity of the afferent nerves from the limb.

CASE 10.-This case showed wasting of the biceps muscle after contusion. A Sergeant received a blow on the front of the humerus just below the shoulder joint. For two months afterwards he complained of pain in this region, with weakness of the shoulder. Examination revealed: (1) gross wasting of the biceps muscle; (2) a well-defined tender spot in its upper fibres, near the musculo-tendinous junction. Infiltration abolished the pain permanently, but many weeks elapsed before the atrophy had recovered.

Reflex wasting is not paralysis; but sometimes an injury is followed by a paresis of a group of muscles supplied by a nerve which could not have been involved in the injury.

CASE 11.-This case was one of dorsal interosseous paresis after a blow on the wrist. A Private knocked his left wrist, and next day it ached. The pain spread to the elbow, and four days later he " reported sick" with numbness in the fingers and loss of power in the hand. No cutaneous sensory loss could be found; but only the slightest flicker of contractility was present in the extensor group of muscles, and flexion of the fingers also was much weakened.

Five weeks later the pain was continuous, though some movement was returning to the muscles. A tender spot was found in the common site three inches below the lateral epicondyle. An injection of procaine relieved the pain without completing the block of the dorsal interosseous nerve. The pain did not return, and he made a good recovery within a few weeks.

CASE 12.-In this case there was suprascapular nerve paralysis after a bullet wound in the region of the lower angle of the scapula. A Private was shot through the left side of the chest in October, 1943. He made a good recovery; but a month later an aching pain commenced behind the shoulder which persisted for a year. Examination ten months after his injury revealed: (1) a healed wound of entry just medial to the inferior angle of the scapula; the bullet itself was resting just behind the 8th costal cartilage; (2) limitation of active abduction to $60^{\circ}$, though there were no adhesions in the scapulohumeral joint; (3) profound wasting of the spinati; there was no evidence that any fibres of the infraspinatus had survived.
Electromyography.-A denervated muscle displays abnormal activity in the shape of fibrillation. Sometimes this phenomenon can be observed with the eye, but as a rule it can be detected only by electromyography. Weddell and others (1944) have observed that the wasted muscles of interstitial neuritis and " radiculitis" give varying responses, depending upon whether or no denervation has been complete. Disordered and increased muscular activity was recorded as a routine from the areas of maximum muscular tenderness in neuritis and fibrositis. This observation was confirmed by Elliott (1944), who recorded also abnormal activity in muscles which were the site of transient tenderness " referred" from an artificial deep lesion.

Muscular wasting, weakness and fibrillation, therefore, all represent disorders of muscular function which can be brought on by somatic agencies through reflex channels.

Deep Reflexes.-An absent ankle-jerk is regarded by many as a criterion of organic interference with nerve tracts; and the same may be said of the diminution of deep reflexes in general. The experiments of Gellhorn and Thompson (1944), however, suggest that reflexes may be abolished as the result of abnormal conditions within the muscle. By causing the triceps muscle to work under ischaemic conditions, continuous aching pain was produced in ten subjects whose triceps reflexes had been particularly brisk. With the onset of the pain, the deep reflex was abolished, to reappear soon after the restoration of the blood flow: There is a close analogy between ischaemic pain and fibrositic pain, and it should not be surprising occasionally to find that the loss of deep reflexes is merely the effect of a deep somatic lesion. Wartenberg (1944) has deprecated the habit of regarding the absence of a single deep reflex as a sign of central nervous disease; the evidence provided by the reflexes, he said, should be weighed only in conjunction with other neurological signs.

\section{Reflex Paralyses}

The interpretation of the spreading paralyses has undergone a number of fluctuations. Weir Mitchell (1872) had no doubt that the manifestations had a physical basis, and he called them reflex paralyses. He suggested, too, that the nerve impulses which bring about the manifestations must run in a direction opposite to the normal. Babinski and Froment (1918) described a large number of cases in wounded French soldiers. They were emphatic that the disorder bore none of the criteria of hysteria, and their reasons today seem convincing. They coined a new word, "physiopathic", for these disorders, indicating that, though the underlying pathology 
was not understood, they had no doubt of its organic nature. They did not subscribe to the commonly accepted view, epitomized in the term " ascending neuritis", which supposed that a toxin from the infected wounds had entered the peripheral nerve filaments and ascended the neuraxon. Walshe (1919), citing a case of sciatic palsy which followed a blow on the heel, observed that infection did not always precede the paralysis. But the late Sir Arthur Hurst (1919) regarded every such case as hysterical, and his view came to prevail. About the majority of these patients there is little that suggests the hysteric; but it is a melancholy fact that many of them do acquire this damaging stigma. Orthodox clinical neurology is based upon rigid anatomical data, and disorders which do not correspond often receive but scant consideration. We should not be surprised, therefore, to find that recent studies upon the organization of the spinal cord and upon the functions of the peripheral nerves suggest the possibility that such a physical basis does exist.

\section{The Sensory Organization of the Cord}

Is the reflex hypothesis of fibrositis (and of interstitial neuritis) consistent with present knowledge of the physiology of the spinal cord? Do pathways exist through which the supposed disordered impulses must travel? The motor organization of the cord, we know, has as its basis movements rather than individual muscles or individual segments of the cord (Sherrington, 1906). A simple reflex movement requires a complicated form of co-ordination which spreads over a large number of segments, bringing about the stimulation of some groups of muscles and the inhibition of others. It is possible that sensory impulses may be subject to an analogous form of co-ordinated spread; indeed the large number of collaterals which proceed from sensory radicles would seem to imply some sort of interlinking of sensory neurons. And recent neurophysiological work seems to indicate that such a sensory reflex organization exists. In addition to the sensory impulses which ascend directly to the cerebrum, delayed discharges of a reflex nature can be recorded which spread upwards in the cord and outwards through the posterior roots (Toennies, 1938; Barron, 1940; Hursh, 1940). "The nervous system ", wrote Lorente de Nó (1938), " is composed of an exceedingly large number of interlacing pathways which offer numerous opportunities for the conduction of impulses into divergent paths; but during activity it becomes fractionated into a group of active and a group of inactive neurones." The integrating mechanisms, in other words, ensure that stimulation and inhibition proceed side by side, in both the motor and the sensory provinces, without becoming deranged. Lorente de Nó used the term " internuncial pool" to describe the neuronal systems through which the impulses are relayed, and the idea was further developed by Livingston in his excellent monograph (1943). Livingston argues convincingly in favour of the reflex hypothesis; it seems that a succession of abnormal sensory impulses (such as may proceed from diseased or damaged tissue), continued over a long period, may permanently damage the integrating mechanism, resulting in a state of imbalance. Thus, if normal stimuli cause certain neurones to be activated and others to be inhibited, prolonged abnormal stimulation may result in intensification and prolongation of the stimulation on the one hand, and of the inhibition on the other. These changes would manifest themselves as intractable motor and sensory abnormalities.

\section{Summary}

1. The pathology of interstitial neuritis remains in a state of obscurity.

2. Radiating pain and perineural tenderness do not constitute sufficient evidence on which to make this diagnosis, for they often represent the secondary effects of a myalgic lesion.

3. The diagnosis should be made only if there is motor or sensory loss to indicate interference with nerve conduction; and even these cases sometimes differ in a striking fashion from proven " lesions in continuity".

4. In thirty-three out of sixty-three cases, the onset of interstitial neuritis could be related to local injury or disease. In most of these it was not likely that the damage could have involved the nerve trunk directly.

5. In some cases the sensory and motor manifestations were observed to spread beyond the fields of any nerves which could have been implicated.

6. These anomalous features are explained in the light of a reflex hypothesis previously proposed for fibrositis.

7. It is an error to diagnose hysteria in these cases. Reference is made to the views of Babinski on reflex paralysis, and to those of Lorente de Nô on the sensory organization of the cord.

\section{REFERENCES}

Adrian, E. D., Cattell, McK., and Hoagland, H. (1931). J. Physiol., 72, 377 and 392.

Babinski, J., and Froment, J. (1918). " Hysteria or Pithiatism." London.

Barron, D. H. (1940). J. Neurophysiol., 3, 403.

Bennett, A. E. (1939). J. Amer. med. Ass., 112, 590. 
Bentley, F. H., and Schlapp, W. (1943). J. Physiol., $102,72$.

Burnard, E. D., and Fox, T. G. (1942). N. Z. med. J., 41, 243.

Clausen, E. G. (1942). Surgery, 12, 933.

Ecker, A. D., and Woltman, H. W. (1938). J. Amer. med. Ass., 110, 1650.

Elliott, F. A. (1944). Annals of the Rheumatic Diseases, 4, 22.

Gellhorn, E., and Thompson, L. (1944). Proc. Soc. Exp. Biol., N.Y., 56, 209.

Harding, A. E. B. (1929). Lancet, 1, 433.

Harman, J. B. (1940). Annals of the Rheumatic Diseases, 2, 101 .

Harris, W. (1926). " "Neuritis and Neuralgia." London.

Head, H., and Sherren, J. (1905). Brain, 28, 116.

Hursh, J. B. (1940). J. Neurophysiol., 3, 166.

Hurst, A. F. (1919). Brit. J. Surg., 6, 579.

Kellgren, J. H. (1938). Clin. Sci., 3, 175.

(1939). Ibid., 4, 35.

Kelly, M. (1945). Annals of the Rheumatic Diseases, 5,1 .

(1946a). Ibid., 5, 69.

- (1946b). Ibid., 5, 161 .

Lewis, T. (1942). " Pain." New York. Macmillan.

Livingston, W. K. (1943). " "Pain Mechanisms." New York. Macmillan.

Lorente de Nó, R. (1938). J. Neurophysiol., 1, 207.

Martin, J. P. (1933). Proc. roy. Soc. Med., 26, 1394.

Miller, D. S., and De Takats, G. (1942). Surg. Gynec. Obstet., 75, 558.

Mitchell, S. W. (1872). "Injuries to Nerves and Their Consequences." Philadelphia. Lippincott.

Nielsen, J. M. (1939). J. Amer. med. Ass., 113, 1801.

Paget, J. (1879). "Clinical Lectures and Essays." London. Longmans.

Richardson, J. S. (1942). Lancet, 1, 618.

Seddon, H. J. (1943). Brain, 65, 237.

Sherrington, C. S. (1906). "The Integrative Action of the Nervous System." London.

Spillane, J. D. (1943). Lancet, 2, 532.

Sunderland, S. (1945). Brain, 68, 56.

Symonds, C. P. (1943). Medical Annual, p. 310.

Thompson, I. M. (1931). J. Anat., 66, 148 (abstract).
Toennies, J. F. (1938). J. Neurophysiol., 1, 378.

Walshe, F. M. R. (1919). Brain, 42, 339.

- (1943). "Diseases of the Nervous System." Edinburgh.

Wartenberg, R. (1944). Arch. Neurol. Psychiat., Chicago, $51,113$.

Weddell, G., Feinstein, B., and Pattle, R. E. (1944). Brain, 67, 178.

Wilson, S. A. K. (1927). Ibid., 50, 428.

\section{Névrite Interstitielle et Théorie Nerveuse de la Cellulite}

RÉSUMÉ

1. La pathologie de la névrite interstitielle reste obscure.

2. La douleur irradiante et la sensibilité périneurale ne constituent pas une preuve suffisante permettant d'établir un diagnostic car elles constituent souvent les effets secondaires d'une lésion musculaire.

3. On ne doit faire ce diagnostic que lorsqu'il existe une déficience motrice ou sensorielle indicatrice d'un trouble de la conduction nerveuse ; et il arrive même que certains de ces cas diffèrent de façon marquée des "lésions en continuité " démontrées.

4. Dans 33 cas sur 63 , on a pu établir une corrélation entre le début de la névrite interstitielle et un traumatisme ou une maladie localisés. Dans la plupart de ces cas il était peu probable que la lésion ait atteint directement le tronc nerveux.

5. Dans certains cas on a observé que les manifestations sensorielles et motrices s'étendaient au-delà du territoire des nerfs qui auraient pu être atteints.

6. Ces anomalies sont expliquées à la lumière d'une théorie réflexe de la cellulite proposée antérieurement.

7. Il est erroné de poser un diagnostic d'hystérie dans ces cas. Cet article se réfère aux vues de Babinski sur la paralysie réflexe et à celles de Lorente de Nó sur l'organisation sensorielle de la moëlle épinière. 